\title{
UNDERSTANDING RESILIENCE AND AGGRESSION IN MIDDLE ADULTHOOD
}

\author{
Sabahat Naseem* \\ Seema Munaf**
}

\begin{abstract}
The ability to be resilient in the face of adversity requires the absence of unhealthy coping behaviors, one of which is aggression. Middle adulthood is the developmental stage of various midlife stressors. Limited data is available with regards to this age group especially in Pakistan. The present study was conducted to determine the relationship between resilience and aggression in middle adulthood. For this purpose, 200 participants (100 men; 100 women) with $M_{\text {age }}=42.67$ years \& SD $=6.04$, from different work places and residential areas of Karachi, Pakistan participated in the study. The Brief Resilience Scale was used to measure resilience whereas aggression was measured using the Short Form of the Buss-Perry Aggression Questionnaire. Pearson product-moment correlation and regression analysis, conducted using the SPSS, indicated the presence of a significant negative correlation between resilience and aggression. This study would help in understanding how resilience and aggression plays a role during middle adulthood. It would further be beneficial for mental health professionals to identify, devise, and implement better ways of enhancing resilience and helping people to deal with adversities in a healthy manner.
\end{abstract}

Keywords: Resilience, aggression, middle adulthood, middle age

\section{Introduction}

Throughout one's lifespan, an individual encounters various inevitable stressors and hardships that require a use of multiple coping strategies. With the pressure of keeping up with the fast-paced life and the fear of being left behind, people deal with the adversities in a variety of ways; from utilizing healthy coping mechanisms and coming out stronger after an adversity to resorting to aggressive behaviors and eventually increasing the complications. Such differences help in identifying different characteristics and vulnerabilities of individuals including resilience and aggression.

Resilience is the ability of an individual to function in a healthy manner during and after dealing with the adversities and traumatic events. A resilient individual has the capability to successfully adapt in spite of the difficult and challenging life situations ${ }^{1}$. On the other hand, aggression typically denotes a variety of behaviors that are almost always likely to cause, either or both, physical and psychological harm to self and/or to others. Aggression can be expressed in many forms such as physical (hitting, kicking, etc.),

\footnotetext{
* Sabahat Naseem, PhD Fellow, Institute of Clinical Psychology, University of Karachi

${ }^{* *}$ Seema Munaf, PhD Meritorious Professor, Institute of Clinical Psychology, University of Karachi

${ }^{1}$ George Bonanno, Maren Westphal, and Anthony Mancini, "Resilience to Loss and Potential Trauma," The

Annual Review of Clinical Psychology 7 (2011), https://doi.org/10.1146/annurev-clinpsy-032210-104526
} 
verbal (yelling, calling names, etc.), anger (an intense negative emotion that usually leads to aggressive acts), hostility (having ill intentions that may lead to hostile behaviors), etc. ${ }^{2}$. Researchers have observed that emotional deregulation is one of the chief characteristics of aggression and that, if aggression is not managed, it has the tendency to become more stable and increase with the passage of time ${ }^{3,4}$.

Theoretical constructs explain the association between resilience and aggression. It has been noted that an individual's tendency to act with resilience decreases his or her chances of exhibiting aggression in the face of stressors. Similarly, higher aggressive tendencies lead towards lower probability of being resilient. Many researchers have noted that if an individual developed aggressive tendencies in early life, he or she is most likely to continue to possess those characteristics later in life as well. This, in turn, tends to increase an individual's chances of maladjustment as well as affects the ability to deal with and bounce back after the adverse life situations in a healthy manner, that is, leads to poor resilience ${ }^{5}$ Kim and his colleagues ${ }^{6}$ found that resilience plays a substantial role in assuaging aggression, depression, anxiety and other emotional disturbances that an adult is likely to suffer due to traumas faced in early life. Additionally, resilience enables a person to manage their emotional as well as behavioral reactions which subsequently decreases the probability of them demonstrating aggressive tendencies upon encountering any challenging situation ${ }^{7}$.

Among the numerous mediating and moderating factors, developmental stage also plays an imperative role in the relationship between resilience and aggression. An individual's skills and capacities to face, adapt, and deal with both positive and negative events in life is characterized by many environmental and socio-cultural factors as well as his or her chronological age. Thus, as each stage of life comes with its own set of anticipated and unanticipated adverse events, the way that people react to and deal with those hard times differs depending on the stage of life they are during that time ${ }^{8}$.

\footnotetext{
2 “APA Dictionary of Psychology: Aggression,” American Psychological Association, Accessed April 14, 2019, https://dictionary.apa.org/aggression

${ }^{3}$ Dan Olweus, "Stability of Aggressive Reaction Patterns in Males: A Review," Psychological Bulletin 86 (1979), http://dx.doi.org/10.1037/0033-2909.86.4.852

${ }^{4}$ John Donahue et al., "Emotion Dysregulation, Negative Affect, and Aggression: A Moderated, Multiple Mediator Analysis," Personality and Individual Differences 70 (2014), https://doi.org/10.1016/j.paid.2014.06.009

${ }^{5}$ Bruce Compas, Beth Hinden, and Cynthia Gerhardt, "Adolescent Development: Pathways and Processes of Risk and Resilience," Annual Review of Psychology, 46 (1995), http://dx.doi.org/10.1146/annurev.ps.46.020195.001405

${ }^{6}$ Joohan Kim et al., "The Protective Role of Resilience in Attenuating Emotional Distress and Aggression Associated with Early-life Stress in Young Enlisted Military Service Candidates," Journal of Korean Medical Science 30, no. 11 (2015), https://doi.org/10.3346/jkms.2015.30.11.1667

${ }^{7}$ Fran Norris et al., "60,000 Disaster Victims Speak: Part I. An Empirical Review of the Empirical Literature, 1981-2001," Psychiatry: Interpersonal and Biological Processes 65, no. 3 (2002), https://doi.org/10.1521/psyc.65.3.207.20173

${ }^{8}$ Maria Cristina Richaud de Minzi and Carla Sacchi, "Stressful Situations and Coping Strategies in Relation to Age," Psychological Reports 97, no. 2 (2005), https://doi.org/10.2466/pr0.97.2.405-418
} 
Middle-adulthood is a time during which many individuals are faced with various midlife crises. In the words of the renowned psychologist, Carl Jung", midlife is the "afternoon of life". The events faced during midlife comprise of both, physical as well as psychological ups and downs that the process of aging generally accompanies. These may range from health issues to stressors related to their responsibilities in their family, work, as well as social life. It is during this stage that individuals have to juggle between multiple challenging tasks and roles that typically include increased financial burden; elevation in care-giving roles such as being parents of adults, taking care of spouses as well as frail parents, playing the role of grandparents; rise in health problems and related concerns; etc. ${ }^{10,11}$. All these life transitions and novel experiences tend to affect how well or poorly individuals in their middle adulthood adapt to and negotiate with the challenges that this stage of development brings along.

With regard to resilience during middle adulthood, researchers have noted that the level of resilience tends to vary over time due to the interplay of several factors that are associated with middle adulthood. As found by Dainese, Allemand, Ribeiro, Baryam, Martin, and Ehlert ${ }^{12}$, the presence of positive emotions impacts physical and psychological health during the middle and older years of life which in turn helps in enhancing the level of resilience. Some researchers have noted that aggressive behaviors and anger tends to increase with the increase in age because, with an amplified exposure to a variety of situations, many adults find it difficult to tackle with the stressors they face in everyday life. Aggression in adulthood is commonly manifested in different ways such as road rage, domestic violence, hostility at workplace, substance use, violation of laws, etc. ${ }^{13}$

Other than developmental phase, the available literature points towards the conception that the development, stability, and modification of both, the level of resilience and aggression, is largely affected by several social, environmental, personal, situational, biological, as well as cultural factors. Among the various protective and risk factors that influence an individual's ways of responding to life events and effect the association between these two variables are self-esteem, gender, coping mechanisms, familial and social relationships, socioeconomic status, personal control, etc. ${ }^{14}$ Furthermore, many researches accentuate that individuals who are prone towards risk-taking attitudes and behaviors such as smoking, alcohol and other substance use, expressing frequent anger and violent behaviors, etc. are maladjusted and lack the ability to handle the stressors of

\footnotetext{
${ }^{9}$ Carl Jung, Modern Man in Search of a Soul (New York: Harcourt, Brace \& World, 1993)

${ }^{10}$ Margie Lachman, "Development in Midlife," Annual Review of Psychology 55 (2004), http://dx.doi.org/10.1146/annurev.psych.55.090902.141521

${ }^{11}$ Toni Antonucci, Hiroko Akiyama, and Alicia Merline, "Dynamics of Social Relationships in Midlife." In Handbook of Midlife Development, ed. Margie Lachman (Hoboken, NJ, US: John Wiley \& Sons Inc., 2001), 571-598.

${ }^{12}$ Sara Dainese et al., "Protective Factors in Midlife: How Do People Stay Healthy?," GeroPsych: The Journal of Gerontopsychology and Geriatric Psychiatry 24, no. 1 (2011): 19-29, http://dx.doi.org/10.1024/16629647/a000032

${ }^{13}$ Jianghong Liu, Gary Lewis, and Lois Evans, "Understanding Aggressive Behavior Across the Life Span," Journal of Psychiatric and Mental Health Nursing 20, no. 2 (2013).

${ }^{14}$ Mary Alvord and Judy Grados, "Enhancing Resilience in Children: A Proactive Approach," Professional

Psychology: Research and Practice 36, no. 3 (2005), http://dx.doi.org/10.1037/0735-7028.36.3.238
} 
life with resilience ${ }^{15}$. Moreover, Hobfoll ${ }^{16}$ explained that an individual's perception and cognitive appraisal also plays a key role in determining a negative event or a stressor. Thus, it is possible that one individual may ascertain an event as negative and would react accordingly whereas, another individual might consider that same event as positive or harmless and therefore, would react according to his or her evaluation of that event.

Even though an ample amount of work has been done on resilience and aggression, there is a major scarcity of research work, especially in Pakistan, that focuses mainly on the relationship between these two variables. Moreover, during the middle stage of life, people's challenges and stressors have a probability of increasing as they do not only have to deal with the current life situations but also have to face the consequences of past experiences along with the variety of concerns generally associated with aging. However, previous researches have overlooked the developmental stage of middle adulthood while studying resilience and aggression and the available literature is heavily loaded with studies on children and adolescent population ${ }^{17}$.

Therefore, the purpose of the present research is to investigate the relationship between resilience and aggression in the population of middle adulthood. This study would be valuable in understanding how individuals experience, combat, and adapt with the challenges that they go through during their middle age. Moreover, keeping the sociocultural problems that middle-aged individuals have been encountering in Pakistan ${ }^{18}$, this study would be beneficial in opening pathways for developing culturally appropriate strategies to promote resilience and mitigating risk factors for aggression particularly during middle stage of life.

\section{Hypothesis}

Considering the literature review, it was hypothesized that: The level of resilience would be negatively correlated with the level of aggression among individuals in middleadulthood.

\section{Method}

\section{Participants}

The sample comprised of total 200 participants including 100 men and 100 women with $M_{\text {ages }}=42.67$ years $\& S D=6.04$. All the participants were selected from four private

\footnotetext{
${ }^{15}$ Nancy Ahern, "Resiliency in Adolescent College Students" (PhD diss., University of Central Florida, Orlando, Florida, 2007), Accessed March 20, 2019,

${ }^{16}$ Stevan Hobfoll, "The Influence of Culture, Community, and the Nested-self in the Stress Process: Advancing Conservation of Resources Theory," Applied Psychology 50, no. 3 (2001). http://dx.doi.org/10.1111/14640597.00062

${ }^{17}$ Debra McGinnis, "Resilience, Life Events, and Well-being During Midlife: Examining Resilience Subgroups," Journal of Adult Development 25, no. 3 (2018): 198-221, https://doi.org/10.1007/s10804-0189288-y

${ }^{18}$ Saniya Sabzwari and Gohar Azhar, "Ageing in Pakistan - A new challenge," Ageing International 36, no. 4 (2011), https://doi.org/10.1007/s12126-010-9082-z
} 
sector workplaces as well as different residential areas of Karachi, Pakistan. As per the requirements of scales used in the study, all the participants' minimum educational level was grade 7 .

\section{Measures}

\section{Respondent Information Form}

The Respondent Information Form was developed to gather basic demographic information that included age, gender, and current educational level, along with other relevant demographic information.

\section{The Brief Resilience Scale (BRS) ${ }^{19}$}

The Brief Resilience Scale (BRS) is based on a self-report format. It has a total of six items. The responses are given in accordance with one's agreement and/or disagreement to each item using a 5-point Likert scale that ranges from 'Strongly Disagree' to 'Strongly Agree'. Three of the items (2, 4, and 6) are reversely scored. The average value of the sum of all items gives the final score. This scale possesses satisfactory psychometric properties with Cronbach's alpha $=0.80$ to 0.91 indicating high internal consistency and test-retest reliability of 0.62 (three months) ${ }^{20}$.

\section{Short Form of the Buss-Perry Aggression Questionnaire (BPAQ - SF $)^{21}$}

The Short Form of the Buss-Perry Aggression Questionnaire (BPAQ - SF) is a selfreport scale. A total of 12 items are used to measure aggression on a whole whereas, with the division of these 12 items into four groups ( 3 items in each group), the scale can also measure four forms of aggression (verbal, physical, hostility, and anger). The responses are given considering to the extent to which each item defines the respondents. The BPAQ-SF uses a 5-point Likert scale for responses ranging from 'Extremely Uncharacteristic of Me' to 'Extremely Characteristic of Me'. The total aggression score is calculated by dividing the sum of all items by 12 , whereas, scores for individual forms of aggression can be calculated by dividing those items' sum by 3 . The BPAQ-SF has satisfactory psychometric properties and has been found to have good test-retest reliability ${ }^{22,23}$.

\footnotetext{
${ }^{19}$ Bruce Smith et al., "The Brief Resilience Scale: Assessing the Ability to Bounce Back," International Journal of Behavioral Medicine 15, no. 3 (2008), https//doi.org/10.1080/10705500802222972

${ }^{20}$ Bruce Smith et al., (2008).

${ }^{21}$ Fred Bryant and Bruce Smith, (2001).

${ }^{22}$ Ruud Hornsveld et al., "Psychometric Properties of the Aggression Questionnaire in Ditch Violent Forensic Psychiatric Patients and Secondary Vocational Students," Assessment 16, no. 2 (2009), https://doi.org/10.1177/1073191108325894

${ }^{23}$ John Gallagher and Jose Ashford, "Buss-Perry Aggression Questionnaire: Testing Alternative Measurement Models with Assaultive Misdemeanor Offenders," Criminal Justice and Behavior 43, no. 11 (2016), https://doi.org/10.1177/0093854816643986
} 


\section{Procedure}

All the approached participants were first briefed about the purpose of the study and were clearly informed that their participation is voluntary and that they have the right to withdraw at any time without any penalties. Additionally, they were also guaranteed regarding the maintenance of confidentiality. After taking their consent, the questionnaires were given to them to fill and they were thanked for their time and cooperation. All through the data collection, the researcher was present for the participants in case they had any queries or required help.

\section{Results}

Results were calculated using the Statistical Package for Social Sciences (SPSS). Pearson product moment correlation was used to analyze the relationship between resilience and aggression whereas simple linear regression analysis was applied to gauge the variance.

Table 1

Descriptive Statistics of Resilience and Aggression

\begin{tabular}{|l|c|c|}
\hline Variables & $\boldsymbol{M}$ & $\boldsymbol{S D}$ \\
\hline Resilience & 3.09 & .87 \\
\hline Aggression & 2.77 & .64 \\
\hline Physical Aggression & 2.33 & .93 \\
\hline Anger & 2.89 & .82 \\
\hline Hostility & 3.04 & .87 \\
\hline Verbal Aggression & 2.71 & .88 \\
\hline
\end{tabular}

$N=200$

Table 1 illustrates the descriptive statistics for the relationship between level of resilience and level of aggression as well as the four forms of aggression (physical aggression, anger, hostility, and verbal aggression).

Table 2

\section{Correlation between the Level of Resilience and Aggression}

\begin{tabular}{|l|c|c|}
\hline \multirow{2}{*}{ Variables } & \multicolumn{2}{|c|}{ Resilience } \\
\cline { 2 - 3 } & $r$ & $p$ \\
\hline Aggression & $-.32^{* *}$ & .00 \\
\hline Physical Aggression & -.11 & .05 \\
\hline Anger & $-.16^{* *}$ & .00 \\
\hline Hostility & $-.32^{* *}$ & .00 \\
\hline Verbal Aggression & $-.15^{*}$ & .01 \\
\hline
\end{tabular}

$* * p<.01, * p<.05, N=200$ 
Table 2 demonstrates inferential statistical results for the relationship between level of resilience and level of aggression. Analysis of results through Pearson product moment correlation showed that there is a significant and negative correlation between the level of resilience and the level of aggression $(r=-.32 * *, p<.01, N=200)$. Further, the relationship of the level of resilience was also analysed with each of the four forms of aggression; physical aggression, anger, hostility, and verbal aggression. A statistically significant relationship of the level of resilience was found with anger $\left(r=-.16^{* *}, p<\right.$ $.01, N=200)$, hostility $\left(r=-.32^{* *}, p<.01, N=200\right)$, and verbal aggression $\left(r=-.15^{*}, p\right.$ $<.01, N=200$ ). However, the negative relationship between resilience and physical aggression was not significant $(r=-.11, p<.01, N=200)$.

\section{Table 3}

\section{Simple Linear Regression Analysis for the Level of Resilience and Aggression}

\begin{tabular}{|c|c|c|c|}
\hline & \multicolumn{3}{|c|}{ Aggression } \\
\hline Variable & $\mathrm{B}$ & SE B & $\beta$ \\
\hline Resilience & -.23 & .04 & $-.32^{* *}$ \\
\hline$R^{2}$ & \multicolumn{3}{|c|}{} \\
\hline$F$ & \multicolumn{3}{|c|}{23.36} \\
\hline
\end{tabular}

$* * p<.01$

Table 3 shows the results of simple linear regression analysis which indicates that the level of resilience accounted for $10.6 \%$ variance in the level of aggression and is statistically significant $(F(1,198)=23.36, p<.00)$.

\section{Discussion}

Pakistan is a developing country and it has been through a variety of adverse social, political, and environmental situations. The ever increasing waves of violence, hostility, and aggression towards minorities and different sects in the country increase the likelihood of disrupting the psychological health of the countrymen ${ }^{24}$.

Considering the results of the present study, in accordance with the hypothesis, level of resilience was found to be negatively correlated with the level of aggression as well as all four of its domains (see Table 2). It was further found that an increase in the level of resilience helps in decreasing the level of aggression among individuals (see Table 3).

Resilience is an ability that helps in dealing well with and being able to adapt during and after the adverse situations. It also helps in recovery and mitigating the harmful effects of the negative events and circumstances, both physically and psychologically and makes a person come back even stronger after going through difficult times ${ }^{25}$. The results of this

\footnotetext{
${ }^{24}$ Muhammad Tahir Khalily et al., "Violence, Psychological Trauma and Possible Acute Post-Traumatic Interventions in Pakistani Society," Australasian Journal of Disaster and Trauma Studies 1 (2011).

${ }^{25}$ Miri Cohen, Svetlana Baziliansky, and Alex Beny, "The Association of Resilience and Age in Individuals with Colorectal Cancer: An Exploratory Cross-Sectional Study," Journal of Geriatric Oncology 5, no. 1 (2014), https://doi.org/10.1016/j.jgo.2013.07.009
} 
study highlight the significance of promoting resilience as it is closely associated with aggression and thus, plays a substantial role in reducing the intensity and likelihood of many destructive and harmful behaviors and attitudes. Reacting with aggression in any circumstance always has a high probability of undesirable consequences and leads to harm to self and/or others whereas acting in a resilient way tends to have fewer, if any, destructive consequences. While it is not always possible to steer clear from aversive situations or the circumstances that may provoke aggressive tendencies, nonetheless, one can learn the ways to resolve the conflicts at hand in a non-aggressive manner and work towards enhancing resilience at any stage of life ${ }^{26}$.

Consistent with results of the present study, a research conducted in Iran showed that after getting a series of trainings on enhancing resilience, a notable decrease in the level of aggression along with an increase in the level of happiness was found among the participants who previously showed aggressive tendencies ${ }^{27}$. Similarly, studying the relationship of resilience with different psychosocial factors, Sharma and Marimuthu ${ }^{28}$ found resilience to have a negative correlation with the expression of anger. Researches show that resilience helps in regulating emotions which and controlling impulsive responses $^{29}$. This ability for emotional regulation helps a resilient individual to be able to resist in the face of adversity instead of acting out and being aggressive. Furthermore, other than having a strong control on their emotions, individuals who are resilient tend to avoid engaging in destructive and violent activities and also disapprove rage and aggression $^{30}$. Resilience also leads an individual to find better and healthier ways of reducing stress such as utilization of relaxation techniques, physical exercise, etc. This inevitably helps in the reduction of anger, anxiety, and other negative emotions ${ }^{31}$. Additionally, a study conducted in Pakistan ${ }^{32}$ highlighted that resilience is also important at workplaces as improvement in the level of resilience increases the likelihood of decreased counterproductive work behaviors (that include destructive behaviors at work such as anger, hostility towards colleagues, and verbal aggression, etc.) and consequently increases the performance of employees.

\footnotetext{
${ }^{26}$ Kietra Winn, "African American Girls and Physical Aggression: A Resilience Study On How Adult African American Women Overcame Physically Aggressive Behavior Post Adolescence" (PhD diss., University of Pennsylvania, Philadelphia, Pennsylvania, 2013), Accessed May 2, 2019, https://repository.upenn.edu/cgi/viewcontent.cgi?article=1052\&context=edissertations_sp2

${ }^{27}$ Bahman Akbari, "Effectiveness of Training Psychological Resilience on Aggression and Happiness among Students," Journal of Holistic Nursing and Midwifery 27, no. 1 (2017).

${ }^{28}$ Manoj Sharma and Palaniappan Marimuthu, "Prevalence and Psychosocial Factors of Aggression among Youth," Indian Journal of Psychological Medicine 36, no. 1 (2014), https://doi.org/10.4103/0253-7176.127249

${ }^{29}$ Nancy Eisenberg and Michael Sulik, "Emotion-related Self-regulation in Children," Teaching of Psychology 39, no. 1 (2012), https://doi.org/10.1177/0098628311430172

${ }^{30}$ Wassilis Kassis et al., "Finding the way out: A Non-dichotomous Understanding of Violence and Depression Resilience of Adolescents Who are Exposed to Family Violence," Child Abuse \& Neglect 37 (2013), https://doi.org/10.1016/j.chiabu.2012.11.001

${ }^{31}$ David Murphey, Megan Barry, and Brigitte Vaughan, “Adolescent Health Highlight: Positive Mental Health - Resilience" (Child Trends, Publication no. 2013-3, 2013). Accessed March 12, 2019, https://www.childtrends.org/wp-content/uploads/2013/03/Child_Trends-2013_11_01_AHH_Resilience.pdf

${ }^{32}$ Sheikh Raheel Manzoor, Ijlal Ahmad Khattak, and Shah Hassan, "Psychological Capital and Counterproductive Work Behaviour with Intrusion of Employee Performance: Study from KP, Pakistan universities," City University Research Journal 5, no. 2 (2015).
} 
Moreover, the present study's results also indicated that among the four domains of aggression, hostility was found to have a stronger negative correlation with resilience compared to the rest of the three domains (see Table 2). These results are also supported by a study conducted by Mojrian, Homayouni, Rahmedani, and Alizadeh ${ }^{33}$ who found resilience to be significantly negatively correlated with aggression and hostility. In addition, Anderson ${ }^{34}$ identified that the ability to control anger has a significant negative correlation with various types of resilience.

Keeping in mind that the present study specifically focused on resilience and aggression in middle adulthood, it is important to consider that some longitudinal studies indicate that the passage of time tends to have an impact on individuals' ways of adapting to different situations in life. It has been noted that by the time individuals reach their middle adulthood, their destructive or aggressive tendencies start to waver and they resort to being resilient in the face of stressors ${ }^{35}$. In addition to this, while some individuals in their middle adulthood are able to competently cope with the hard times, for some it becomes a challenge due to their previous adverse experiences ${ }^{36}$. While reinforced resilience is certainly not the case with all individuals in their middle adulthood, it does, however, points toward the possibility of protective factors available during the middle stage of life such as increased experiences, lessons learnt from the consequences of past aggressive and destructive behaviors, etc. These factors were not taken into account in the present study and which acted as a limitation.

As discussed in the literature review, there is a variety of mediating and moderating factors that play substantial roles in the relationship between aggression and resilience. These factors typically include social support, level of intelligence, sense of achievement and loss, family relationships, physical and psychological health, etc. ${ }^{37}$ One of these factors, social support, has been largely studied with respect to resilience and aggression $^{38}$. Research evidence shows that strong social relationships act as major protective factor for resilience and, consequently, acts as risk factor for anger and related aggressive tendencies ${ }^{39}$. As noted by several researchers, middle adulthood is that stage of development when an individual goes through a many predictable and unforeseen transitions which could be due to loss of employment, children leaving the house,

\footnotetext{
${ }^{33}$ Fatemah Mojrian et al., "Correlation between Resilience with Aggression and Hostility in University Students," European Psychiatry 41 (2017), https://doi.org/10.1016/j.eurpsy.2017.01.969

${ }^{34}$ Mauren Anderson, "The Relationship Among Resilience, Forgiveness, and Anger Expression in Adolescents" (PhD diss., University of Maine, United States, 2006), Accessed March 4, 2019,

https://digitalcommons.library.umaine.edu/cgi/viewcontent.cgi?article=1439\&context=etd

${ }^{35}$ Emmy Werner, "Resilience and Recovery: Findings from the Kauai Longitudinal Study", Focal Point: Research, Policy, and Practice in Children's Mental Health 19, no. 1 (2005).

${ }^{36}$ American Association for Retired Persons, In The Middle: A Report On Multicultural Boomers Coping with Family and Aging Issues (Washington, D.C., 2001). Accessed May 9, 2019, https://assets.aarp.org/rgcenter/il/in_the_middle.pdf

${ }^{37}$ Eric Dubow et al., "Childhood and Adolescent Risk and Protective Factors for Violence in Adulthood," Journal of Criminal Justice 45 (2016), http://dx.doi.org/10.1016/j.jcrimjus.2016.02.005

${ }^{38}$ Fatih Ozbay et al., "Social Support and Resilience to Stress: From Neurobiology to Clinical Practice," Psychiatry 4, no. 5 (2007).

${ }^{39}$ Okan Bilgin and Ibrahim Tas, "Effects of Perceived Social Support and Psychological Resilience on Social Media Addiction among University Students," Universal Journal of Educational Research 6, no. 4 (2018), https://doi.org/10.13189/ujer.2018.060418
} 
physical health problems, etc. This transition directly impacts the individual's interpersonal relationships and emotional state. Keeping in mind the influence of social support, it can be attributed that the transitions of middle adulthood make people vulnerable to changes in the level of resilience and aggression as well.

\section{Conclusion}

Considering the objectives of the present study, the relationship between resilience and aggression was investigated in middle adulthood. The findings indicated that resilience and aggression have a statistically significant negative correlation.

\section{Limitations of the Study}

In addition, considering other limitations of the present study, the collection of data from only one city of Pakistan limits the generalizability of the findings throughout the country. Therefore, collecting data from other cities would assist in expanding the understanding of the study's objectives.

Moreover, several risk and protective factors during the middle stage of life that has an impact on the middle-aged individuals' level of resilience and aggression were not taken into account in the present study which would have helped analyzing the relationship between resilience and aggression in more depth.

\section{Recommendations and Avenues for Future Research}

Despite the fact that both resilience and aggression are crucial components and should be given attention during early years, the significance of fostering resilience while managing aggression throughout the lifespan cannot be denied. Fortunately, resilience is a capability that, if not already present, can be learned at any stage of life ${ }^{40}$. Therefore, it is possible and substantial for adults to focus on building resilience and reinforcing it in later years as well.

It is a well-known fact that when people are repeatedly exposed to daily life stressors such as inflation, load-shedding, increased traffic on the roads; it tends to severely impact them negatively and leads toward different psychological, emotional, and behavioral difficulties. Research evidences point towards the notion that resilience is an ability that is vital in promoting positive mental health and that resilient people have the knowledge and capacity to deal with stressors without the demonstration of any severe psychopathologies unlike individuals who are non-resilient ${ }^{41}$. Moreover, various researchers have highlighted time and again that in order for the interventions that are intended to build and enhance resilience to be strengthened, the strategies should not only focus on working towards the reduction of the risk factors but it would be more beneficial

\footnotetext{
40 "Resilience Guide for Parents \& Teachers," American Psychological Association, Accessed April 29, 2019, https://www.apa.org/helpcenter/resilience

${ }^{41}$ Joohan Kim et al., (2015).
} 
to also consider the ways through which the protective factors can be stimulated and reinforced ${ }^{42}$.

In addition, for future studies, while studying the relation of resilience with aggression, it is recommended to focus on the different components and ways through which resilience can be manifested such as help-seeking behavior, thinking in a positive manner, etc. As some studies indicate that it may be possible that one component of resilience is more effective in moderating and mediating aggression than the other ${ }^{43}$. This would help in focusing on specific constituents while strategizing ways to build and foster resilience.

Lastly, keeping in mind the stressors that the people of Pakistan go through on a daily basis, it would be beneficial in developing strategies to build and enhance resilience and teaching people healthier ways of dealing with anger. Now is the high time to introduce learning and development programs focusing on building resilience and anger management as they have been shown to work effectively in producing various positive outcomes such as reducing mental distress and vulnerability, improving interpersonal relationships, etc. ${ }^{44}$ Empirical evidence indicates that the fundamental factors of such interventions include different cognitive restructuring techniques, stress coping skills, awareness raising sessions, enhancing social skills, modification of behaviors, etc. ${ }^{45}$ These training programs should be tailored in accordance with the need of different age groups and should not only be introduced in education institutes and government and private organizations but should also be conducted in different communities of the country so that people from all walks of life can be catered and get benefit from them.

\section{Bibliography}

Ahern, Nancy. "Resiliency in Adolescent College Students." PhD diss., University of Central Florida, Orlando, Florida, 2007. Accessed March 20, 2019. http://etd.fcla.edu/CF/CFE0001627/Ahern_Nancy_R_200705_phd.pdf

Akbari, Bahman. "Effectiveness of training psychological resilience on aggression and happiness among students." Journal of Holistic Nursing and Midwifery 27, no. 1 (2017). Accessed May 1, 2019. http://hnmj.gums.ac.ir/article-1-806-en.pdf

\footnotetext{
${ }^{42}$ John Pollard, David Hawkins, and Michael Arthur, "Risk and Protection: Are both Necessary to Understand Diverse Behavioral Outcomes in Adolescence?," Social Work Research 23, no. 3 (1999), https://doi.org/10.1093/swr/23.3.145

${ }^{43}$ Reuben Ng, Rebecca Ang, and Moon-Ho Ringo Ho, "Coping with Anxiety, Depression, Anger and Aggression: The mediational Role of Resilience in Adolescents," Child \& Youth Care Forum 41, no. 6 (2012), http://dx.doi.org/10.1007/s10566-012-9182-x

${ }^{44}$ Parvaneh Haddadi and Mohammad Ali Besharat, "Resilience, Vulnerability, and Mental Health," Procedia Social and Behavioral Sciences 5 (2010), https://doi.org/10.1016/j.sbspro.2010.07.157

${ }^{45}$ Tamara Del Vecchio and Daniel O'Leary, "Effectiveness of Anger Treatments for Specific Anger Problems: A Meta-analytic Review," Clinical Psychology Review 24 (2004), https://doi.org/10.1016/j.cpr.2003.09.006
} 
Alvord, Mary, and Judy Grados. "Enhancing resilience in children: A proactive approach." Professional Psychology: Research and Practice 36, no. 3 (2005): 238-245. http://dx.doi.org/10.1037/0735-7028.36.3.238

American Association of Retired Persons. In The Middle: A Report On Multicultural Boomers Coping with Family and Aging Issues. Washington, D.C., 2001. Accessed May 9, 2019. https://assets.aarp.org/rgcenter/il/in_the_middle.pdf

American Psychological Association. "APA Dictionary of Psychology: Aggression." Accessed April 14, 2019. https://dictionary.apa.org/aggression

American Psychological Association. "Resilience Guide for Parents \& Teachers." Accessed April 29, 2019. https://www.apa.org/helpcenter/resilience

Anderson, Mauren. "The Relationship Among Resilience, Forgiveness, and Anger Expression in Adolescents." PhD diss., University of Maine, United States, 2006). Accessed March 2019. https://digitalcommons.library.umaine.edu/cgi/viewcontent.cgi article=1439\&context=et d

Antonucci, Toni, Hiroko Akiyama, and Alicia Merline. "Dynamics of Social Relationships in Midlife." In Handbook of midlife development, edited by Margie Lachman, 571-598. Hoboken, NJ, US: John Wiley \& Sons Inc., 2001.

Bilgin, Okan and Ibrahim Tas. "Effects of perceived social support and psychological resilience on social media addiction among university students." Universal Journal of Educational Research 6, no. 4 (2018). https://doi.org/10.13189/ujer.2018.060418

Bonanno, George, Maren Westphal, and Anthony Mancini. "Resilience to loss and potential trauma." The Annual Review of Clinical Psychology, 7 (2011). https://doi.org/10.1146/annurev-clinpsy-032210-104526

Bryant, Fred and Bruce Smith. "Refining the architecture of aggression: A measurement model for the Buss-Perry Aggression Questionnaire." Journal of Research in Personality 35 (2001): 138-167. http://dx.doi.org/10.1006/jrpe.2000.2302

Cohen, Miri, Svetlana Baziliansky, and Alex Beny. "The association of resilience and age in individuals with colorectal cancer: An exploratory cross-sectional study." Journal of Geriatric Oncology 5, no. 1 (2014). https://doi.org/10.1016/j.jgo.2013.07.009

Compas, Bruce, Beth Hinden, and Cynthia Gerhardt. "Adolescent development: Pathways and processes of risk and resilience." Annual Review of Psychology, 46 (1995). http://dx.doi.org/10.1146/annurev.ps.46.020195.001405

Dainese, Sara, Mathias Allemand, Nadja Ribeiro, Sanem Bayram, Mike Martin, and Ulrike Ehlert. Protective factors in midlife: How do people stay healthy? GeroPsych: The Journal of Gerontopsychology and Geriatric Psychiatry 24, no. 1 (2011). http://dx.doi.org/10.1024/1662-9647/a000032 
Donahue, John, Anders Goranson, Kelly McClure, and Lynn Van Male. "Emotion dysregulation, negative affect, and aggression: A moderated, multiple, mediator analysis." Personality and Individual Differences $70 \quad$ (2014). https://doi.org/10.1016/j.paid.2014.06.009

Dubow, Eric, Rowell Huesmann, Paul Boxer, and Cathy Smith. "Childhood and adolescent risk and protective factors for violence in adulthood." Journal of Criminal Justice 45 (2016): 26-31. http://dx.doi.org/10.1016/j.jcrimjus.2016.02.005

Eisenberg, Nancy and Michael Sulik. "Emotion-related self-regulation in children." Teaching of Psychology 39, no. 1 (2012). https://doi.org/10.1177/0098628311430172

Gallagher, John and Josh Ashford. "Buss-Perry Aggression Questionnaire: Testing alternative measurement models with assaultive misdemeanor offenders." Criminal Justice and Behavior 43, no. 11 (2016). https://doi.org/10.1177/0093854816643986

Haddadi, Parvaneh and Mohammad Ali Besharat. "Resilience, vulnerability, and mental health." Procedia - Social and Behavioral Sciences 5 (2010). https://doi.org/10.1016/j.sbspro.2010.07.157

Hobfoll, Steven. "The influence of culture, community, and the nested-self in the stress process: Advancing conservation of resources theory." Applied Psychology 50, no. 3 (2001). http://dx.doi.org/10.1111/1464-0597.00062

Hornsveld, Ruud, Peter Muris, Floris Kraaimaat, and Cor Meesters. "Psychometric properties of the aggression questionnaire in Ditch violent forensic psychiatric patients and secondary vocational students." Assessment 16, no. 2 (2009). https://doi.org/10.1177/1073191108325894

Jung, Carl. Modern Man in Search of a Soul. (New York: Harcourt, Brace \& World, 1993).

Kassis, Wassilis, Sibylle Artz, Christian Scambor, Elli Scambor, and Stephanie Moldenhauer. "Finding the way out: A non-dichotomous understanding of violence and depression resilience of adolescents who are exposed to family violence." Child Abuse \& Neglect 37 (2013). https://doi.org/10.1016/j.chiabu.2012.11.001

Khalily, Muhammad Tahir, Suzane Foley, Ijaz Hussain, and Maher Bano. "Violence, psychological trauma and possible acute post-traumatic interventions in Pakistani society." Australasian Journal of Disaster and Trauma Studies 1 (2011). Accessed March 10, 2019, http://trauma.massey.ac.nz/issues/2011-1/khalily.htm

Kim, Joohan, Jeong-Ho Seok, Kang Choi, Duk-In Jon, Hyun Ju Hong, Narei Hong, and Eunjeong Lee. "The protective role of resilience in attenuating emotional distress and aggression associated with early-life stress in young enlisted military service candidates." Journal of Korean Medical Science 30, no. $11 \quad$ (2015). https://doi.org/10.3346/jkms.2015.30.11.1667 
Lachman, Margie. "Development in midlife." Annual Review of Psychology 55 (2004): 305-331. http://dx.doi.org/10.1146/annurev.psych.55.090902.141521

Liu, Jianghong, Gary Lewis, and Lois Evans. "Understanding aggressive behavior across the life span." Journal of Psychiatric and Mental Health Nursing 20, no. 2 (2013): 156168. https://www.ncbi.nlm.nih.gov/pmc/articles/PMC3411865/\#

Manzoor, Sheik Raheel, Ijlal Ahmad Khattak, and Shah Hassan. "Psychological capital and counterproductive work behaviour with intrusion of employee performance: Study from KP, Pakistan universities." City University Research Journal 5, no. 2 (2015). Accessed March 29, http://www.cityuniversity.edu.pk/curj/Journals/Journal/July\%202015/15.pdf

McGinnis, Debra. "Resilience, life events, and well-being during midlife: Examining resilience subgroups." Journal of Adult Development 25, no. 3 (2018): 198-221. https://doi.org/10.1007/s10804-018-9288-y

Minzi, Maria Cristina Richaud de and Carla Sacchi. "Stressful situations and coping strategies in relation to age." Psychological Reports 97, no. 2 (2005): 405-418. https://doi.org/10.2466/pr0.97.2.

Mojrian, Fatemah, Aziz Homayouni, Zakieh Rahmedani, and Mohammad Alizadeh. "Correlation between resilience with aggression and hostility in university students." European Psychiatry 41 (2017). https://doi.org/10.1016/j.eurpsy.2017.01.969

Murphy, David, Megan Barry, and Brigitte Vaugh. "Adolescent health highlight: Positive mental health - Resilience." (Child Trends, Publication no. 2013-3, 2013). Accessed March 12, 2019. https://www.childtrends.org/wp-content/uploads/2013/03/Child_Trends2013_11_01_AHH_Resilience.pdf

$\mathrm{Ng}$, Reuben, Rebecca Ang, and Moon-Ho Ringo Ho. "Coping with anxiety, depression, anger and aggression: The mediational role of resilience in adolescents." Child \& Youth Care Forum 41, no. 6 (2012). http://dx.doi.org/10.1007/s10566-012-9182-x

Norris, Fran, Matthew Friedman, Patricia Watson, Christopher Byrne, Eolia Diaz, and Krzysztof Kaniasty. " 60,000 disaster victims speak: Part I. An empirical review of the empirical literature, 1981-2001." Psychiatry: Interpersonal and Biological Processes 65, no. 3 (2002). https://doi.org/10.1521/psyc.65.3.207.20173

Olweus, Dan. "Stability of aggressive reaction patterns in males: A review." Psychological Bulletin 86 (1979): 852-875. http://dx.doi.org/10.1037/0033-2909.86.4.852

Ozbay, Fatih, Douglas Johnson, Eleni Dimoulas, Charles Morgan, Dennis Charney, and Steven Southwick. "Social support and resilience to stress: From neurobiology to clinical practice." Psychiatry 4, no. https://www.ncbi.nlm.nih.gov/pmc/articles/PMC2921311/ 
Pollard, John, David Hawkins and Michael Arthur. "Risk and protection: Are both necessary to understand diverse behavioral outcomes in adolescence?." Social Work Research 23, no. 3 (1999). https://doi.org/10.1093/swr/23.3.145

Sabzwari, Saniya and Gohar Azhar, "Ageing in Pakistan - A new challenge." Ageing International 36, no. 4 (2011). https://doi.org/10.1007/s12126-010-9082-z

Sharma, Manoj and Palaniappan Marimuthu. "Prevalence and psychosocial factors of aggression among youth." Indian Journal of Psychological Medicine 36, no. 1 (2014): 48-53. https://doi.org/10.4103/0253-7176.127249

Smith, Bruce, Jeanne Dalen, Kathryn Wiggins, Erin Tooley, Paulette Christopher and Jennifer Bernard. "The Brief Resilience Scale: Assessing the ability to bounce back." International Journal of Behavioral Medicine 15, no. 3 (2008). doi:10.1080/10705500802222972

Vecchio, Tamara Del and Daniel O'Leary, "Effectiveness of anger treatments for specific anger problems: A meta-analytic review." Clinical Psychology Review 24 (2004). https://doi.org/10.1016/j.cpr.2003.09.006

Werner, Emmy. "Resilience and recovery: Findings from the Kauai longitudinal study." Focal Point: Research, Policy, and Practice in Children's Mental Health 19, no. 1 (2005): 11-14. Accessed May 2, 2019. https://www.pathwaysrtc.pdx.edu/pdf/fpS0504.pdf

Winn, Kietra. “African American Girls and Physical Aggression: A Resilience Study On How Adult African American Women Overcame Physically Aggressive Behavior Post Adolescence." PhD diss., University of Pennsylvania, Philadelphia, Pennsylvania, 2013. $\begin{array}{llll}\text { Accessed May } & \text { Ma19. }\end{array}$ https://repository.upenn.edu/cgi/viewcontent.cgi?article=1052\&context=edissertations_s 